\title{
Expressão imuno-histoquímica e valor prognóstico da proteína p53 no carcinoma de vesícula biliar: estudo de 60 casos
}

\author{
Immunohistochemical expression and prognostic value of the $p 53$ protein in gallbladder carcinoma: \\ a 60-case study
}

Andréa Oxley da Rocha'; Lígia Maria Barbosa Coutinho²; Laís Dal Pino Leboute ${ }^{3}$; João Grigoletti Scholl ${ }^{4}$

Unitermos
Vesicula biliar
p53
Neoplasia de vesícula biliar
Prognóstico

\section{resumo}

Base teórica/objetivo: Poucos estudos, com pequenas amostras e resultados divergentes, têm sido realizados para avaliar a expressão da proteína p53 no carcinoma de vesícula biliar e sua relação com diferentes parâmetros clinicopatológicos. Baseados nesses fatos realizamos um estudo com objetivo de avaliar a expressão do p53 nessa afeccção e sua associação a fatores prognósticos. Material e método: Amostras de 60 casos de carcinoma de vesícula biliar foram avaliadas por técnica imuno-histoquímica quanto à expressão da proteína p53 e analisadas em relação ao prognóstico, avaliado através do sistema de estádio TNM e Nevin, sobrevida e outros parâmetros clinicopatológicos. Resultados: A expressão p53 foi positiva em $58,3 \%$ dos tumores malignos de vesícula biliar. Não foi observada associação estatisticamente significante entre a expressão dessa proteína e fatores prognósticos, tipo ou grau histológico, presença de cálculos ou sobrevida. Conclusão: A mutação do gene p53 está, muito provavelmente, envolvida na patogênese do carcinoma de vesícula biliar. Entretanto não parece haver, de acordo com nossos dados, associação entre a expressão da proteína p53 e o prognóstico ou a sobrevida dos pacientes portadores dessa afeç̧ão.

Background/aims: Few studies, with small samples and diverging results, have been performed to evaluate the p53 protein expression in gallbladder carcinoma and its relationship to different clinicopathological parameters. Based on these facts, we performed a study for the purpose of assessing p53 expression in this disease and its association to prognostic factors. Material and method: Samples of 60 consecutive cases of gallbladder carcinoma were assessed to evaluate the $p 53$ protein expression using the immunohistochemical technique (streptoavidinbiotin-peroxidase) and their relationship with survival and prognosis factors was studied. The prognosis of this neoplasm was performed using the Nevin classification and TNM staging system. Results: $p 53$ expression was positive in $58.3 \%$ of carcinomas of the gallbladder. No association was found between p53 protein expression and prognostic factors, histological type or grade, presence of gallstones and survival. Conclusion: The mutation of gene 53 is probably involved in the pathogenesis of the gallbladder carcinoma. Our data does not show an association between $p 53$ protein expression and survival or prognostic factors.

1. Mestre em Medicina pela Universidade Federal do Rio Grande do Sul; cirurgiã do Serviç̧o de Cirurgia Geral do Hospital Mãe de Deus.

2. Professora titular e livre-docente de Anatomia Patológica da Fundação Faculdade Federal de Ciências Médicas de Porto Alegre.

3. Cirurgiã do Serviço de Cirurgia Ceral do Hospital Mãe de Deus.

4. Médico patologista do Crupo Hospitalar Conceição.

Trabalho realizado na Fundação Faculdade Federal de Ciências Médicas de Porto Alegre (FFFCMPA).

Artigo baseado em dissertação de mestrado intitulada Avaliação da Presença de Expressão da Proteína p53 e Receptores de Estrogênio e Progesterona em Espécimes Cirúrgicos de Vesícula Biliar, com defesa pública realizada em 2 de outubro de 2003, no Programa de Pós-Graduação em Medicina: Ciências Médicas, da Faculdade de Medicina da Universidade Federal do Rio Grande do Sul. 


\section{Introdução}

A neoplasia maligna de vesícula biliar é considerada uma afecção pouco freqüente e, ainda hoje, associada a um curso rapidamente letal. Entretanto, apesar da baixa freqüência, essa neoplasia representa $0,7 \%$ a $1,2 \%$ de todos os carcinomas ${ }^{(22)}$ e ocupa o $5^{\circ}$ lugar entre as neoplasias do trato digestivo ${ }^{(4,5,7)}$. Além disso, o CaVB é o tumor maligno mais comum do trato biliar, correspondendo a aproximadamente $1 \%$ a $3 \%$ das peças de colecistectomia ${ }^{(4,27)}$. Séries brasileiras ${ }^{(21,}$ ${ }^{24)}$ confirmam esses dados, tendo Ziliotto et al. ${ }^{(45)}$ relatado uma incidência de 1,02\% de CaVB como achado incidental em 885 colecistectomias realizadas por colecistite.

A incidência do carcinoma de vesícula biliar varia amplamente nas diferentes partes do mundo $(4,11,17)$, sendo mais freqüente em alguns países da América Latina e na Índia. No Chile essa afecção encontra-se em terceiro lugar como causa de óbito quando comparada a todas as neoplasias, sendo a segunda entre os tumores do trato digestivo com uma elevada incidência de 13 por 100 mil habitantes. Na Índia incide em cerca de 4,5 por 100 mil habitantes na população masculina, atingindo níveis de 10,1 entre as mulheres do norte desse país. Altas incidências também são relatadas em Israel, Polônia, México e Bolívia. Nos Estados Unidos é uma neoplasia incomum, com uma incidência de 1,1 por 100 mil habitantes para o sexo masculino e 2,2 para o sexo feminino $^{(3,17,22,32-34)}$. Em Porto Alegre, Brasil, é responsável por 3,09 óbitos por 100 mil habitantes ${ }^{(6)}$.

Apesar do grande progresso atingido no tratamento dos tumores malignos do trato digestivo, o carcinoma de vesícula biliar (CaVB) persiste sendo uma exceção. $\mathrm{O}$ prognóstico desse tumor é pobre e, na maioria das séries, apresenta taxa de sobrevida de no máximo $5 \%$ em cinco anos, já que menos de $10 \%$ dos pacientes se apresentam com tumor ressecável no momento do diagnóstico, sendo a média de sobrevida inferior a seis meses $(11,26,34,35)$.

Atualmente, já está estabelecido na literatura que o carcinoma invasivo de vesícula biliar é precedido por lesões pré-malignas - displasia e carcinoma in situ - fato que fornece um bom modelo para o estudo das anormalidades genéticas e da progressão neoplásica ${ }^{(42)}$. Essas anormalidades epiteliais têm sido bem caracterizadas como um continuum de modificações citológicas, refletindo alterações gênicas importantes na patogênese da neoplasia ${ }^{(41)}$. No entanto, apesar dos recentes avanços na carcinogênese molecular de várias neoplasias malignas, o mecanismo patogênico envolvido na progressão de uma lesão pré-maligna para carcinoma invasivo de vesícula biliar ainda não está completamente esclarecido.
O câncer, de maneira geral, resulta de alterações gênicas múltiplas, ocorrendo, com freqüência, rearranjos genéticos variados que podem ativar ou inativar genes. Vários estudos ${ }^{(10,16,36)}$ têm mostrado que anormalidades do gene p53 estão envolvidas na gênese de aproximadamente $50 \%$ das neoplasias malignas ${ }^{(37)}$. O gene $\mathrm{p} 53$ se localiza no braço curto do cromossoma 17, atuando como inibidor da proliferação celular (antioncogene) ${ }^{(42)}$. Esse gene pode ser alterado por mutações variadas que ocorrem em vários locais de sua extensão. Por esse motivo, muitos agentes mutagênicos podem levar à sua modificação. A mutação de um alelo do gene p53 é muitas vezes acompanhada por uma deleção do outro alelo, resultando na formação de um produto protéico inativo ${ }^{(9)}$. A proteína mutante p53 inativa a proteína $\mathrm{p} 53$ normal ocasionando perda da função de supressão tumoral desse gene, o que permite a atividade oncogênica. A proteína p53 é metabolicamente lábil, sendo rapidamente degradada no núcleo e provavelmente por esse motivo é usualmente indetectável em células de tecidos normais. A forma mutante dessa proteína exibe um aumento de sua meia-vida, podendo ser detectada por

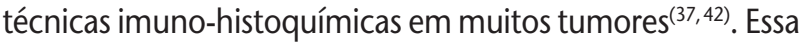
mutação parece desempenhar um importante papel na patogênese de muitas neoplasias malignas, como câncer gástrico ${ }^{(9)}$, de cólon ${ }^{(43)}$, mama ${ }^{(38)}$, pulmão(12) e esôfago ${ }^{(30)}$, sendo incomum em tumores benignos ${ }^{(12)}$. A correlação da expressão da proteína p53 com a mutação gênica no CaVB foi avaliada em estudo recente realizado por Itoi et al.(13), que demonstraram uma sensibilidade de $56,5 \%$ da mutação p53, especificidade de $90 \%$ e validade de 1,47.

Desde a primeira publicação realizada por Kamel et al.(16) em 1993 para avaliar imuno-histoquimicamente a presença de expressão da proteína p53 no CaVB, poucas publicações ${ }^{(1, ~ 8, ~ 9, ~ 13, ~ 16, ~ 18, ~ 20, ~ 25, ~ 28, ~ 29, ~ 36, ~ 39, ~ 40, ~ 42) ~ t e ̂ m ~ s i d o ~ f e i t a s, ~ c o m ~}$ achados bastante variáveis de positividade (entre $36,9 \%$ e $95 \%$ ) e conflitantes em relação à associação dessa mutação com o prognóstico dos portadores dessa neoplasia.

Nesse sentido, realizamos este estudo para avaliar através de imuno-histoquímica a presença de expressão da proteína p53 no CaVB e sua associação com sobrevida e fatores prognósticos, analisados através da classificação de Nevin ${ }^{(23)}$ e sistema de estádio TNM (American Joint Committee on Cancer, 1997) ${ }^{(2)}$.

\section{Metodologia}

Sessenta casos consecutivos de CaVB foram coletados dos arquivos do Departamento de Patologia da FFFCMPA, 
no período de 1980 a 1993. Os prontuários hospitalares desses pacientes foram revisados para obtenção de dados clínicos pertinentes. Os óbitos foram verificados junto à Secretaria de Saúde do estado do Rio Grande do Sul e cartórios de registros de óbitos.

A partir dos blocos de parafina, o diagnóstico histológico foi novamente confirmado, e foi realizada a técnica imuno-histoquímica para identificação da expressão da proteína p53. O método utilizado foi a estreptavidinabiotina-peroxidase. Os cortes foram desparafinados em xilol e reidratados com etanol e água. Um tratamento preliminar, para recuperação antigênica foi aplicado por aquecimento das lâminas no microondas em solução de citrato de sódio, revertendo o efeito da fixação pelo formol. A atividade da peroxidase endógena foi bloqueada por imersão das lâminas em solução com $\mathrm{H}_{2} \mathrm{O}_{2}$ a $0,3 \%$ e metanol por 30min. A seguir as lâminas foram lavadas duas vezes com solução tampão de fosfato (PBS) a $4^{\circ} \mathrm{C}$ por $20 \mathrm{~min}$ e após em soro normal por $20 \mathrm{~min}$. $\mathrm{O}$ anticorpo primário utilizado foi o monoclonal antiproteína p53 produzido em rato (Dako Corporation, D0-7) na concentração de 1:500, permanecendo durante a noite em refrigerador. Após nova lavagem com PBS, os cortes foram encubados com anticorpo secundário antiimunoglobulina de rato por $30 \mathrm{~min}$ e a seguir em complexo estreptavidina-biotina-peroxidase por 30min na diluição de 1:200 e lavados com PBS. A ligação antígeno-anticorpo foi visualizada com diaminobenzidina (DAB) e contracorada com hematoxilina. Utilizamos como controle positivo cortes de tumor de mama (previamente confirmados como positivos para p53), e negativo, lâminas desse mesmo tumor substituindo-se o anticorpo primário por soro fisiológico.

Para análise da reatividade do p53, consideramos positivos somente aqueles casos nos quais houve inequívoca coloração homogênea do núcleo das células em marrom. A avaliação utilizada foi a mesma proposta por Teh ${ }^{(36)}$, baseada na quantidade de núcleos corados na lâmina examinada, sendo divida em três categorias: com menos de $10 \%$, entre $10 \%$ e $50 \%$ e com mais de $50 \%$ dos núcleos das células tumorais corados. A intensidade da coloração também foi dividida em moderada e forte intensidade. $\mathrm{O}$ tumor foi considerado positivo somente quando havia intensa coloração de mais de $10 \%$ das células tumorais ou moderada coloração de mais de $50 \%$ das células.

A avaliação da associação entre a expressão da proteína p53 e o prognóstico dessa neoplasia foi realizada utilizandose os fatores prognósticos validados por Henson ${ }^{(11)}$ em 1992, através da classificação $\mathrm{Nevin}^{(23)}$ (1976) e do sistema de estádio TNM ${ }^{(2)}$ para avaliação do estágio da doença. Também pesquisamos associação da presença dessa proteína com grau e tipo histológico das lesões. Para fins de análise estatística dividimos os casos de CaVB em duas categorias: precoces (estágios I e II de Nevin e I e II do sistema TNM) e avançados (estágios III, IV e V de Nevin e III e IV TNM), de acordo com os critérios de Sato et al. ${ }^{(31)}$.

As análises estatísticas utilizadas para avaliar a associação entre parâmetros clinicopatológicos e a reatividade do p53 foram o teste do qui-quadrado e o teste exato de Fisher. A análise da sobrevida foi realizada através da curva de Kaplan-Meier.

\section{Resultados}

Nos 60 casos estudados a média de idade foi de 62 anos, sendo que $86,7 \%$ dos pacientes se apresentavam com mais de 50 anos ao diagnóstico. Oitenta e seis por cento (52) dos pacientes portadores de CaVB eram do sexo feminino.

A presença de expressão da proteína p53 foi observada em 58,3\% (35) dos casos de CaVB (Figura 1). Cálculos biliares estavam presentes em $83,3 \%$ dos portadores de CaVB (52 pacientes), entretanto não foi observada diferença estatisticamente significativa, em relação à positividade do p53 na ausência ou na presença de cálculos. Todos os resultados dos parâmetros clinicopatológicos avaliados podem ser observados na Tabela 1.

Em relação ao tipo histológico, 88,3\% (53) eram adenocarcinomas, $10 \%$ (seis) carcinomas adenoescamosos e $1,7 \%$ (um) indiferenciado. A reatividade para o p53 foi positiva em $58,55 \%$ dos adenocarcinomas, $50 \%$ dos tumores adenoescamosos e o tumor indiferenciado também apresentaram expressão dessa proteína.

Entre os tumores considerados precoces (classificação de Nevin), 37,5\% (três) apresentaram expressão da proteína p53, bem como 61,5\% (32) dos carcinomas invasivos, não havendo diferença estatisticamente significativa entre esses dois grupos. Similarmente, no sistema de estadiamento TNM não houve significância nas diferenças encontradas, nos casos de doença inicial ou doença avançada, em relação à expressão da proteína p53. O mesmo observou-se em relação a grau histológico e demais parâmetros clinicopatológicos analisados (Tabela 1).

Apesar de se tratar de casos de arquivo, foi possível avaliar a sobrevida de 42 pacientes (70\%). A média de sobrevida dos pacientes portadores de CaVB foi de 9,9 meses (desvio padrão de 2,56) e mediana de 3,97 meses. 


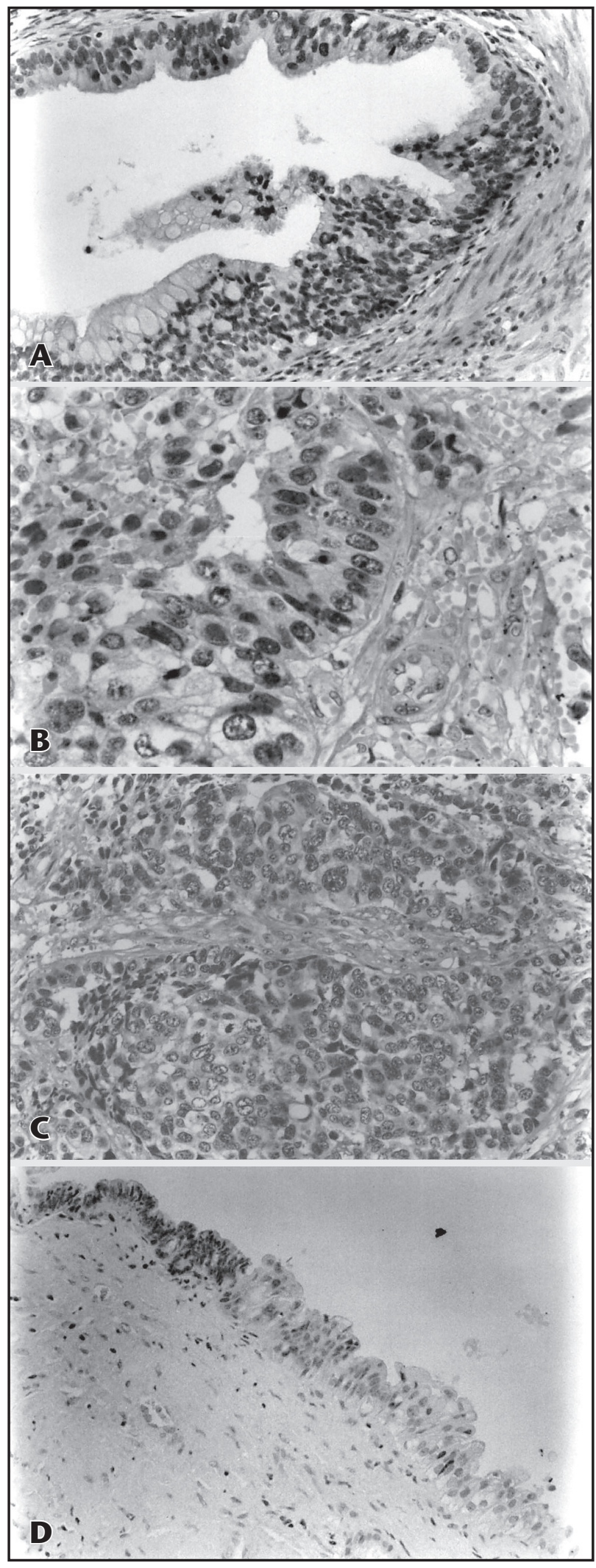

Figura 1 - A: Adenocarcinoma moderadamente diferenciado de vesícula positivo para p53 (20x); B: adenocarcinoma pouco diferenciado de vesícula com núcleos das células neoplásicas demonstrando imunorreatividade para proteína p53 (40x); C: carcinoma pouco diferenciado de vesícula com intensa positividade da proteína p53 (20x); D: carcinoma adenoescamoso de vesícula biliar: epitélio adjacente à neoplasia mostrando a transição entre áreas negativas (sem neoplasia) e positivas (epitélio com displasia) para o p53 (10x)
Não houve associação entre a expressão da proteína p53 e o tempo de sobrevida (Figura 2).

\section{Discussão}

Além das dificuldades de reconhecimento dos fatores envolvidos na gênese do carcinoma de CaVB biliar, o próprio quadro clínico inespecífico dificulta o diagnóstico precoce dessa afecção(15) e mesmo esta sendo a mais comum malignidade do trato biliar, é sempre diagnosticada em estágios avançados ${ }^{(17)}$. Esses fatos têm motivado a constante busca da compreensão, ainda incerta, da carcinogênese dessa neoplasia.

Vários estudos $(1,8,9,13,16,18,20,25,28,29,36,39,40,42)$ foram realizados para avaliar a presença de expressão da proteína p53 no CaVB, apresentando resultados conflitantes tanto em relação à sua positividade quanto à significância da imunorreatividade no prognóstico dessa neoplasia. Esse fato pode ser atribuído, em parte, a pequenas amostras estudadas. Além disso, as discrepâncias observadas em relação à positividade do p53 também podem estar relacionadas aos diferentes anticorpos utilizados nos estudos. Kamel et al. ${ }^{(16)}$ e Ajiki et al.(1) utilizaram anticorpo policlonal CM1 e apresentaram menor imunorreatividade que a maioria dos autores que utilizaram anticorpo monoclonal D07 e PAb1801, que reconhecem epitopos diferentes daqueles reconhecidos pelo CM1. Essas diferenças podem ser observadas na Tabela 2.

Não se observou associação entre a imunorreatividade do p53 e os índices prognósticos avaliados (Tabela 1), o que sugere que a expressão dessa proteína não esteja

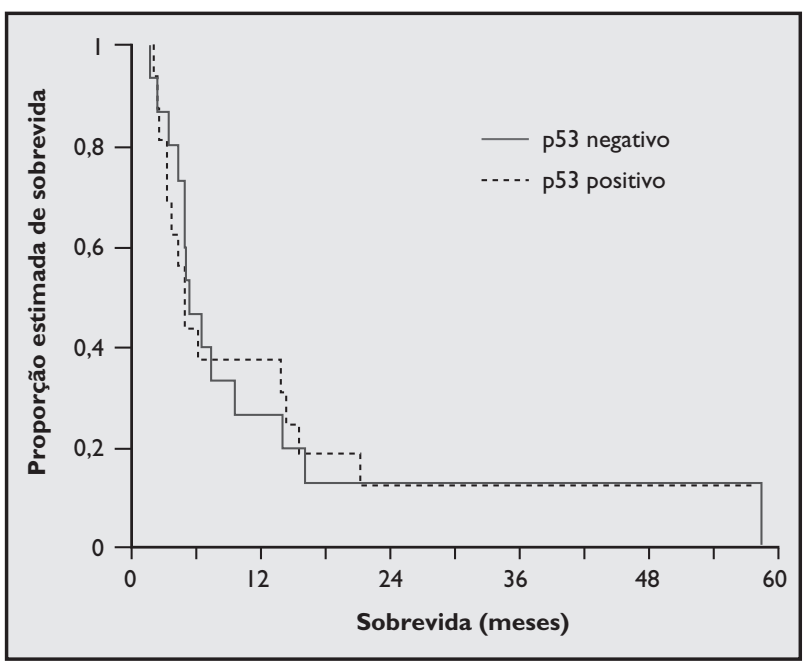

Figura 2 - Sobrevida dos pacientes com carcinoma de vesícula conforme a expressão da proteína $p 53$ 
Associação da imunorreatividade p53 com aspectos clinicopatológicos e fatores prognósticos

Tabela 1 no carcinoma de vesícula biliar

\begin{tabular}{|c|c|c|c|}
\hline Parâmetro & $\mathrm{N}^{0}$ de casos & $\mathrm{N}^{0}$ de p53 positivos (\%) & Valor de $p$ \\
\hline Sexo & & & $0,44^{*}$ \\
\hline Feminino & 52 & $29(55,8)$ & \\
\hline Masculino & 8 & $6(75)$ & \\
\hline Idade & & & $0,7^{*}$ \\
\hline$<50$ anos & 8 & $4(40 \%)$ & \\
\hline$\geq 50$ anos & 52 & $31(59,6)$ & \\
\hline Associação c/cálculos & & & $1^{*}$ \\
\hline Presente & 50 & $29(55,6)$ & \\
\hline Ausente & 10 & $6(60)$ & \\
\hline Estágio TNM & & & $0,14^{*}$ \\
\hline I e II & 9 & $3(33)$ & \\
\hline III e IV & 51 & $32(62,7)$ & \\
\hline Classificação de Nevin & & & $0,26^{*}$ \\
\hline I e II & 8 & $3(37,5)$ & \\
\hline III, IV e V & 52 & $32(61,5)$ & \\
\hline Grau histológico $^{\dagger}$ & & & $0,71^{*}$ \\
\hline Bem diferenciado & 13 & $8(61,5)$ & \\
\hline Moderadamente diferenciado & 28 & $15(53,6)$ & \\
\hline Pouco diferenciado & 12 & $8(66,7)$ & \\
\hline
\end{tabular}

*Valores de p não-significativos; ${ }^{\dagger}$ referente aos 53 casos de adenocarcinoma.

\section{Tabela 2 de vesícula}

\section{Estudos imuno-histoquímicos que avaliam a expressão da proteína p53 no carcinoma}

\begin{tabular}{lccc}
\hline Autores & $N^{0}$ de casos & Positividade p53 $(\%)$ & Anticorpo \\
Kamel et al. ${ }^{(21)}, 1993$ & 30 & $14(47)$ & Policlonal CM1 \\
Teh et al. ${ }^{(22)}, 1994$ & 24 & $22(92)$ & Monoclonal D07 \\
Wee et al. ${ }^{(32)}, 1994$ & 24 & $22(92)$ & Monoclonal D07 \\
Diamantis et al. ${ }^{(34)}, 1995$ & 11 & $8(72,7)$ & Policlonal CM1, monoclonal D07 \\
Oohashi et al. ${ }^{(33)}, 1995$ & 41 & $35(85,4)$ & Monoclonal PAb1801 \\
Wistuba et al. ${ }^{(19)}, 1996$ & 52 & $34(65,4)$ & Monoclonal Ab-6 \\
Ajiki et al. ${ }^{(36)}, 1996$ & 48 & $19(39,6)$ & Policlonal CM1 \\
Washington et al. ${ }^{(37)}, 1996$ & 12 & $7(58)$ & Monoclonal Ab-2 \\
Fujii et al. ${ }^{(25)}, 1996$ & 65 & $36(55)$ & Monoclonal D07 \\
Roa et al. ${ }^{(35)}, 1997$ & 191 & $86(45)$ & Monoclonal Ab-6 \\
Itoi et al. ${ }^{(30)}, 1997$ & 33 & $23(69,6)$ & Monoclonal PAb1801 \\
Misra et al. ${ }^{(38)}, 2000$ & 20 & $14(70)$ & Monoclonal D07 \\
Kim et al. $.^{(31)}, 2001$ & 71 & $48(67,6)$ & Monoclonal D07 \\
Quan et al. ${ }^{(39)}, 2001$ & 24 & $15(65)$ & Monoclonal D07 \\
Este estudo & 60 & $35(58,3)$ & Monoclonal D07 \\
\hline
\end{tabular}


relacionada com a progressão tumoral ou a disseminação metastática, semelhante às observações de Ajiki et al. (1) (em 48 pacientes). Roa et al. ${ }^{(29)}$ relataram $45 \%$ de positividade do p53 em 191 carcinomas de vesícula biliar, observando maior positividade entre os carcinomas invasivos (122) do que nas lesões precoces (24). Entretanto, em razão do pequeno número de lesões precoces avaliadas por esses autores, esses dados devem ser avaliados com parcimônia.

No nosso estudo não foram encontradas diferenças que atingissem significância estatística em relação à expressão da proteína p53 nos parâmetros prognósticos analisados. A julgar pela magnitude de algumas diferenças observadas (por exemplo, na classificação de Nevin: $38 \%$ e $62 \%$ ) poderia se atribuir o achado não-significativo, do ponto de vista estatístico, ao pequeno tamanho da amostra (pequeno número de casos de tumor precoce), o que pode acarretar um baixo poder estatístico.

Também não observamos associação entre o tempo de sobrevida nos pacientes com ausência ou presença de imunorreatividade p53, o que concorda com os achados de Kim et al. ${ }^{(18)}$ e Ajiki et al. ${ }^{(1)}$.

O elevado índice de pacientes em que o diagnóstico é tardio, aliado à curta sobrevida observada nesses pacientes, demonstra o benefício da detecção precoce desse carcinoma e, sem dúvida, o estudo dos fatores de risco parece ser ainda o instrumento disponível mais acessível para identificação dos pacientes de risco potencial para desenvolvimento dessa neoplasia. No entanto, a prevenção primária para o carcinoma de vesícula não parece ser esperada em um futuro próximo ${ }^{(19)}$. Mesmo sendo o tipo e o grau histológico fatores prognósticos úteis, o estágio da doença é, provavelmente, o mais confiável fator prognóstico na opinião da maioria dos autores ${ }^{(11,23)}$. Pacientes nos quais o tumor está confinado à vesícula no momento do diagnóstico apresentam melhor prognóstico do que aqueles nos quais o tumor tenha se propagado ao fígado ou a linfonodos regionais, sendo que os melhores resultados, em termos de sobrevida, são observados em pacientes com carcinoma in situ ou precoce cujo diagnóstico é feito em espécimes retirados por colelitíase ${ }^{(11)}$.

Nossos dados, em uma amostra expressiva de 60 casos, demonstraram não haver associação entre a expressão da proteína p53 e a presença de cálculos biliares no CaVB (Tabela 1). Recentemente, Misra et al.(20), avaliando apenas 20 casos de CaVB, relataram 70\% de imunorreatividade para proteína p53, observando significativa correlação entre CaVB associado com cálculos e hiperexpressão do p53. Relação inversa foi observada por Ajiki et al.(1) em 48 casos estudados, sugerindo associação entre o CaVB sem cálculos e a mutação do gene p53, indicando diferentes caminhos para a carcinogênese dessa neoplasia, sendo esta influenciada ou não pelo estímulo dos cálculos. Kamel et al.(16) avaliaram 30 casos de CaVB não observando significância estatística na diferença encontrada na presença ou na ausência de cálculos.

Yanagisawa et al. ${ }^{(44)}$, em recente publicação, relatam que o processo inflamatório está associado a um aumento da renovação celular, sendo as células danificadas eliminadas por apoptose, concluindo que embora o dano no DNA devido à colecistite crônica não esteja completamente esclarecido, o achado de hiperexpressão da proteína p53 sugere que a injúria genômica possa ocorrer, freqüentemente, nas células epiteliais na colecistite crônica. Esse fato, associado à proliferação, pode contribuir para a carcinogênese, embora necessitem identificação desconhecidos co-fatores.

Atualmente, a hipótese proposta para a associação entre a presença de colelitíase e o CaVB é que, no nível molecular, o processo inflamatório crônico desencadeado pela presença dos cálculos possa determinar, ao longo do tempo, a ocorrência de uma mutação alelo-específica, ou seja, perda da heterozigosidade do gene p53 e hiperexpressão da proteína p53 mutante (inativa) ${ }^{(35)}$. A partir dessa mutação, considera-se que possa resultar a transformação maligna na mucosa da vesícula. Entretanto, na ausência de cálculos, deve-se pressupor a existência de outros fatores que possam desencadear a ocorrência dessa mutação, sugerindo-se a ocorrência de diferentes mecanismos envolvidos na sua patogênese. Muito embora essa associação seja plausível e aceita, a prevenção dessa neoplasia através da colecistectomia profilática na colelitíase assintomática, em populações de alto-risco, ainda é assunto controverso(32).

Apesar das observações divergentes, parece haver consenso de que a mutação do gene $\mathrm{p} 53$ deve desempenhar papel crucial na carcinogênese da neoplasia maligna de vesícula biliar. No entanto, com base em nossas observações e na ampla revisão da literatura pertinente, realmente não parece haver associação da expressão dessa proteína com sexo, idade, grau e tipo histológico, presença de cálculos biliares e os fatores prognósticos analisados.

Experimentos laboratoriais recentes ${ }^{(14)}$ têm demonstrado que a inserção de um gene p53 normal em células tumorais resulta em uma diminuição significativa da oncogênese. Isso sugere que a inserção de p53 normal em tumores de pacientes portadores de câncer, usando abordagem de terapia gênica, pode, a princípio, tornar-se uma possibilidade de tratamento para essa neoplasia. 


\section{Referências}

I.AJIKI,T. et al. P53 protein expression and prognosis in gallbladder carcinoma and premalignant lesions. Hepatogastroenterology, v. 43, p. 521-6, 1996.

2. ALBORES-SAAVEDRA, J.; HENSON, D. E.; SOBIN, L. H. The $\mathrm{WHO}$ histological classification of tumors of the gallbladder and extrahepatic bile ducts. A commentary on the second edition. Cancer, v. 70, n. 2, p. 4I 0-4, 1992.

3. ARETXABALA, $X$. et al. Gallbladder cancer in Chile: a report on 54 potentially resectable tumors. Cancer, v. 69, n. I, p. 60-5, 1992.

4. BARBOSA-COUTINHO, L. M. et al. Carcinoma de vesícula biliar: estudo de 26 casos. Rev. AMRIGS, v. 36, n. I, :p. 9-14, 1992.

5. BHASKARAN, V. Hormonal receptors in carcinoma of the gallbladder. Trop Gastroenterol 2000, v. 21, n. 2, p. 48-50, 2000.

6. BRUMINI, R:;ORLONI,H. Câncer no Brasil:Dados Histopatológicos 1976-1980, Rio de Janeiro: Ministério da Saúde, 1982.

7. CUNHA, J. E.; PENTEADO, S.; JUKEMURA, J. Neoplasias da vesícula biliar. In: KALIL, A. N.; COELHO, J. Fígado e Vias Biliares: Clínica e Cirurgia. I ed. Rio de Janeiro: Editora Revinter 200।. p. 650-7.

8. DIAMANTIS, I. et al. P53 protein immunoreactivity in extrahepatic bile duct and gallbladder cancer: correlation with tumor grade and survival. Hepatology, v. 22, n. 3, p. 774-9, 1995.

9. FUJII, K. et al. High frequency of p53 gene mutation in adenocarcinomas of the gallbladder. Cancer Epidemiology, Biomarkers \& Prevention, v. 5, p. 461-6, 1996.

10. GREENBLATT, M. S. et al. Mutations in the p53 tumor suppressor gene: clues to cancer etiology and molecular pathogenesis. Cancer Res, v. 54, p. 4855-78, 1994.

I I. HENSON, D. E.;ALBORES-SAAVEDRA, J:; CORLE, D. Carcinoma of the gallbladder. Histologic types, stage of disease, grade, and survival rates. Cancer, v. 70, n. 6, p. 1493-7, 1992.

12. IGGO, R. et al. Increased expression of mutant forms of $p 53$ oncogene in primary lung cancer. Lancet, v. 335, p. 675-9, 1990.

I 3. ITOI, T. et al. Correlation of p53 protein expression with gene mutation in gallbladder carcinomas. Pathol Int, v. 47, n. 8, p. 525-30, 1997

I4. JORDE, L. B.; CAREY, J. C. Genética do câncer. In: JORDE, L. B.; CAREY, J. C. Genética Médica. 2 ed. Rio de Janeiro: Editora Guanabara Koogan. p. 197-212.

15. JUKEMURA, J. Câncer de vesícula biliar. In: GAYOTTO, L. C. C.; ALVES, V. A. F. Doenças do Fígado e Vias Biliares. I ed. São Paulo: Editora Atheneu, 200 I. p. 1039-47.

16. KAMMEL, D. et al. P53 and c-erbB-2 protein expression in adenocarcinomas and epithelial dysplasias of the gallbladder. J Pathol, v. 170, p. 67-72, 1993.

17. KAUSHIK, S. P. Current perspectives in gallbladder carcinoma. J Gastroenterol Hepatol, v. 16, n. 8, p. 848-54, 2001.

I 8. KIM, Y.W. et al. Expression of the c-erb-B2 and p53 protein in gallbladder carcinomas. Oncol Rep, v. 8, n. 5, p. I 127-32, 2001 .
19. LAZCANO-PONCE, E. C. et al. Epidemiology and molecular pathology of gallbladder cancer. Cancer J Clin, v. 5 I, p. 34964, 2001 .

20. MISRA, S. et al. Overexpression of p53 protein in gallbladder carcinoma in North India. Eur J Surg Oncol, v. 26, p. 164-7, 2000.

2 I. MONTEIRO, M. C. Câncer da vesícula biliar:análise de 100 casos operados. Arq Bras Med, v. 59, p. 337-44, 1985.

22. NAKAYAMA, F. Recent progress in the diagnosis and treatment of carcinoma of the gallbladder. World J Surg, v. I5, p. 313-4, 1991.

23. NEVIN, J. E. et al. Carcinoma of the gallbladder: staging, treatment and diagnosis. Cancer, v. 37, p. 141-8, 1976.

24. NIGRO, A. J.T. et al. Câncer da vesícula biliar. Ann Paul Med Cir, v. 105, p. 63-70, 1978

25. $\mathrm{OHASHI}$, Y. et al. P53 immunostaining distinguishes malignant from benign lesions of the gallbladder. Pathol Int, v. 45, n. I, p. 58-65, 1995.

26. OUCHI, K.; MATSUNO, S.; SATO, T. Long-term survival in carcinoma of the biliary tract. Analysis of prognostic factors in 146 resections. Arch Surg, v. 124, p. 248-52, 1989.

27. PANDEY, M.; PATHAK, A. K.; AMITABH, G. Carcinoma of the gallbladder: a retrospective review of 99 cases. Dig Dis Sci, p. 46, n. 6, p. ||45-5|, $200 \mid$.

28. QUAN, Z.W. et al. Association of p53, p 16, and vascular endothelial growth factor protein expressions with the prognosis and metastasis of gallbladder cancer. J Am Coll Surg, v. 193, n. 4, p. 380-3, 2001.

29. ROA, l. et al. P53 tumor suppressor gene protein expression in early and advanced gallbladder carcinoma. Histopathology, v. 31 , p. 226-30, 1997.

30. SASANO, $\mathrm{H}$. et al. Expression of $\mathrm{p} 53$ in human esophageal carcinoma: an immunohistochemical study with correlation to proliferating cell nuclear antigen expression. Hum Pathol, v. 23, p. 1238-43, 1992.

3 I. SATO, T. et al. Early carcinoma of gallbladder. Gastroenterol Jpn, v. 16, p. 459-64, 1981.

32. SHETH, S.; BEDFORD, A.; CHOPRA, S. Primary gallbladder cancer: recognition of risk factors and role of prophylactic cholecystectomy. Am J Gastroenterol, v. 95, n. 6, p. I402-10, 2000.

33. STROM, B. L. et al. Risk factors for gallbladder cancer. An international collaborative case-control study. Cancer, v. 76, n. 10, p. 1747-56, 1995

34. SUMIYOSHI, K.; NAGAI, E.; CHIJIIWA, F. Pathology of carcinoma of the gallbladder. World J Surg, v. 15, p. 315-21, 1991.

35. TAZUMA, S.; KAJIYAMA, G. Carcinogenesis of malignant lesion of the gallbladder. Langenbeck's Arch Surg, v. 386, n. 3, p. 224-9, 2001 .

36. TEH, M. et al. An immunohistochemical study of p53 protein in gallbladder and extrahepatic bile duct/ampullary carcinomas. Cancer, v. 74, n. 5, p. 142-45, 1994.

37. TOBIAS, E. S.; BLACK, D. M. The molecular biology of cancer. In: RIMON, D. L.; CONNOR, J. M. Principles of Medical 
Genetics. $4^{\text {th }}$. ed. London: Harcourt Publishers Limited, 2002. p. 533-7.

38. WALKER, R. A. et al. Expression of p53 protein in infiltrating and in situ breast carcinomas. J Pathol 1991, v. 165, p. 203II, 1991.

39. WASHINGTON, K.; GOTTFRIED, M. R. Expression of p53 in adenocarcinoma of the gallbladder and bile ducts. Liver, $v$. 16, p. 99-104, 1996.

40.WEE,A.;TEH, M.; RAJU, G. C. Clinical importance of $\mathrm{p} 53$ protein in gallbladder carcinoma and its precursor lesions. J Clin Pathol, v. 47, p. 453-6, 1994.

4I. WISTUBA, I. I. et al. Allele specific mutations involved in the pathogenesis of endemic galllbladder carcinoma in Chile. Cancer Res, v. 55, n. 25। I-5, 1995.
42. WISTUBA, I. I. et al. P53 protein overexpression in gallbladder carcinoma and its precursor lesions: an immunohistochemical study. Hum Pathol, v. 27, n. 4, p. 360-5, 1996.

43. YAMAGUCHI, A. et al. Expression of p53 protein in colorectal cancer and its relationship to short-term prognosis. Cancer, v. 70, p. 2778-84, 1992.

44. YANAGISAWA, N. et al. Enhanced cell kinetics, p53 accumulation and high p2l expression in chronic cholecystitis: comparison with background mucosa of gallbladder carcinomas. Histopathology, v. 36, n. I, p. 54-6I, 2000.

45. ZILIOTTO, J. A.; KUNZLE, J. E.; SGARBI, E. C. Carcinoma primário de vesícula biliar. Rev Bras Cancerol, v. 31 , p. 103-6, 1985. 